\title{
Letters
}

Website: bmj.com

Email: letters@bmj.com

\section{Globalisation and health}

\section{Informed and open debate on globalisation and health is needed}

EDITOR-We live in extraordinary times, but not for the reasons that Feachem celebrates in his eulogy on globalisation as "mostly good for your health." An informed, inclusive discussion of globalisation's merits and demerits, including its impacts on human health, is needed, given the increasingly polarised nature of this debate. The mass demonstrations of anti-capitalist protesters at major international meetings, most recently at the G8 summit in Genoa, Italy, communicate the angst felt by many for the human, social, and environmental consequences of the kind of globalisation we are experiencing today. But the violence that has accompanied these demonstrations has undermined and confused the protestors' message.

For the health community, a fuller review of the evidence begins with a disentangling of globalisation as a complex web of cause and effect. ${ }^{2}$ Both sides of the debate have abused the term as a catch all to explain many natural and human induced changes. Defining globalisation as openness does not capture the multiple, often contradictory, forces at play. Globalisation can also

\section{Advice to authors}

We prefer to receive all responses electronically, sent directly to our website. Processing your letter will be delayed unless it arrives in an electronic form.

We are now posting all direct submissions to our website within 24 hours of receipt and our intention is to post all other electronic submissions there as well. All responses will be eligible for publication in the paper journal.

Responses should be under 400 words and relate to articles published in the preceding month. They should include $\leqslant 5$ references, in the Vancouver style, including one to the BMJ article to which they relate. We welcome illustrations.

Please supply each author's current appointment and full address, and a phone or fax number or email address for the corresponding author. We ask authors to declare any competing interest. Please send a stamped addressed envelope if you would like to know whether your letter has been accepted or rejected.

Letters will be edited and may be shortened.

bmj.com

letters@bmj.com be defined as processes that are changing the ways in which people interact across boundaries, notably physical (such as the nation-state), temporal (such as instantaneous communication via email), and cognitive (such as cultural identity). The result is a redefining of human societies across many spheres-economic, political, cultural, technological and so on. As such, globalisation affects the health of different people in very different ways. How good or bad globalisation happens to be for you will be influenced by socioeconomic status, sex, education, age, geographical location, and other factors.

We are only beginning to understand these interconnections, but existing evidence about the adverse health impacts of globalisation cannot be readily dismissed. The role of global environmental change on diseases such as malaria, dengue fever, and cholera has been well documented. The alarming rise of tobacco related diseases has followed recent global economic policies. The claim that globalisation will ultimately bring greater wealth, and thus better health, is open to challenge. What is needed is a comprehensive examination of the data bearing on each of the many components of globalisation, an assessment of the risks and benefits of each component, and innovative policy responses enabling us to act appropriately when choices are possible, and to adapt to changes that are inevitable. ${ }^{5}$ To do otherwise will reinforce a simplistic debate that is not only widely divided already, but will ultimately fail to benefit the health of all people.

Kelley Lee senior lecturer

kelley.lee@lshtm.ac.uk

David Bradley professor

Mike Ahern research assistant

Centre on Globalisation, Environmental Change

and Health, London School of Hygiene and

Tropical Medicine, London WC1E 7HT

Tony McMichael professor

Colin Butler PhD student

National Centre for Epidemiology and Population Health, Australian National University, Canberra, Australian Capital Territory 0200, Australia

1 Feachem RGA. Globalisation is good for your health mostly. BMJ 2001;323:504-6. (1 September.)

Lee K. Globalisation and health: An introduction. London: Palgrave (in press).

Intergovernmental Panel on Climate Change. Third assessment report. Cambridge: Cambridge University Press, 2001.

4 Yach D, Bettcher D. Globalisation of tobacco industry influence and new global responses. Tobacco Control 2000;9:206-16

5 Weisbrot M, Naiman R, Kim J. The emperor has no clothes: declining economic growth rates in the era of globalization. Washington, DC: Center for Economic and Policy Research, 2001. (CEPR briefing Paper.)
Challenges of globalisation deserve better than simplistic polemics

EDITOR-Feachem argues that globalisation facilitates economic growth and creates benefits, and that the protesters have no alternative policies. ${ }^{1}$ His argument is weak in logic, selective in its evidence, unbalanced in its coverage, sweeping in its generalisation, and egregious in misrepresenting the people whom Feachem describes as opposed to globalisation. Polemical sneering is no more constructive than breaking shop windows.

Industry and trade are the sectors where wealth is produced and where the distribution of wealth is determined. To narrow the income gap and the health gap must entail creating the conditions for productive industry and mutually beneficial trade. But the structures and rules that currently determine the production and distribution of wealth are biased in favour of the rich strata of the rich countries.

The global economy faces a continuing threat of crisis because of the overhang of accelerating productivity over constrained demand. Increasingly efficient production for increasingly global markets reduces aggregate employment and therefore demand. Corporations see sluggish demand growth as a threat to profits and respond by cost cutting and expanding market share. Both reduce the buying power of the labour force and further threaten profits and reinforce the need for strategies of cost cutting and market share.

Meanwhile, levels of consumption are maintained through:

- Increasing household debt in the developed world (as corporate profit is diverted from new investment, parked in the financial sector, and available for consumer credit)

- Bubble consumption among small shareholders (as a result of overly optimistic income expectations associated with inflated asset values)

- Increasing consumption by the new global middle class, including wealthy minorities in low and middle income countries

- Flow of funds from the economies of the developing world to the banks of the developed world through national debt repayment

- Flow of value from the developing countries to the developed countries through unfair trading relations

- Conversion of environmental assets into current income flows.

The structured unfairness of the current regulatory régime is necessary to defer the crisis by maintaining the net flow of value 
from south to north. Continuing poverty, displacement, violence, and wide inequalities are the costs of maintaining these stabilising flows. We should be building positive discrimination into the regulation of global trade in favour of the poorer countries rather than the reverse.

David Legge associate professor

School of Public Health, La Trobe University, Melbourne 3057, Australia

1 Feachem RGA. Globalisation is good for your health, mostly. BMJ 2001;323:504-6. (1 September.)

\section{Globalisation should be supported}

EDITOR-The electronic responses to Feachem's paper confirm the belief prevailing in public health circles that globalisation can only be bad for public health. ${ }^{1}$ Some facts might help. ${ }^{2}$ International trade has been going on for hundreds of years. It has grown in the past few decades because of easier, cheaper, and more efficient transport and near instantaneous communications. Trade even between unequal partners is better for everyone than no trade at all, since it is not a zero sum game. Most trade occurs among countries at a similar stage of development, and most economic activity is still locally determined and regulated.

Governments constantly have to choose between promoting the interests of consumers and protecting those of producers and workers. In general they should think of consumers first. International trade has in the past been exploitative, as illustrated by slavery. It has become less so with international institutions such as the World Trade Organisation trying (albeit with limited success) to set the rules.

The power of multinational corporations and their brands has been exaggerated. They come and go, and nimble footed upstarts constantly threaten them. Free trade, like technological development, creates a few losers but many more winners. Globalised trade has on the whole created far more winners than losers. ${ }^{2}$ The antiglobalisation movement has become a convenient forum for people with diverse interests and agendas to pursue their selfish goals: trade unionists want to protect jobs, and anarchists need a target. The public health lobby has unquestioningly got caught up in the fashionable rhetoric of the moment.

Globalisation has become a convenient scapegoat for the failings of governments to prevent monopoly power. To blame any rise in inequality on global trade as opposed to fiscal and other policies pursued by governments is simplistic and xenophobic. Worse, it is potentially damaging to the prospects of poorer countries to improve their lot sooner rather than later. ${ }^{3}$ The fact is that trade is the only way for poorer countries rapidly to catch up with the rich world. We need more, not less, trade. Rather than reject globalisation the public health lobby should fight for a world trading system based on the principles of freedom and liberty and oppose the tendencies of vested interests in rich countries to use it as a vehicle for trade protectionism on spurious environmental or human welfare grounds.

Jammi N Rao public health physician Gorway Lodge, Walsall WS1 3BB

1 Feachem RGA. Globalisation is good for your health, mostly. BMJ 2001;323:504-6. (1 September.)

2 Micklethwait J, Wooldridge A. A future perfect. The challenge and hidden promise of globalization. New York: Crown Business, 2000.

3 Editorial. The real losers from Seattle. Ecomomist 1999 Dec $11: 15$

\section{Author's reply}

Editor-As I say in my paper and as the September issue of the bulletin of the World Health Organization elaborates, globalisation encompasses events and processes that threaten public health and the interests of poorer people in poorer countries. These dangers and adverse consequences require serious research and action. Some are now receiving a heightened response-for example tobacco, under the leadership of the World Health Organization and with considerable support from the World Bank. Other risks and consequences of globalisation remain to be adequately addressed, especially in the areas of infection and the environment

Globalisation is not a panacea. Many national and international policies and actions are also necessary to ensure sustained growth, alleviation of poverty, and health gain. In addition, some problems remain intractable and the solutions elusive. This is nowhere more apparent than in the desperate situation of some African countries, now worsened by the HIV/AIDS pandemic.

The multicountry econometric analyses (some of which I cite), however, and the documented experience of individual countries, make clear that participation in the global economy promotes economic growth and that economic growth, on average, increases the incomes of the poor. What is good for the incomes of poor people is good for their health. I pointed out in my paper that these relations do not apply everywhere and always, and this is a matter of grave concern requiring careful analysis and strenuous action. Globalisation also brings social and political benefits, especially to poor and oppressed people, which are typically overlooked in the literature on globalisation and health.

There is a mainstream view on globalisation and development, which is generally correct and supported by the evidence. ${ }^{1}$ Then there is the common view in the health community, which is notably more negative. It is this presumption of guilt that leads respectable medical journals to publish statements to the effect that globalisation has increased poverty or health inequity without citation or with only circular citation to earlier unsupported assertions. As I in my paper and Rao in his letter point out, the matter is far more complex and there is good evidence that globalisation reduces poverty and inequity.

An extreme and ideological response to globalisation negates the real benefits of globalisation to the poor and therefore undermines their interests. It also weakens the important messages concerning the adverse health consequences of globalisation and the need for action to ameliorate them. Only when the health community joins the mainstream of the debate will we have the influence that we deserve and the ability to protect and improve the health of people everywhere.

\section{Richard G A Feachem professor}

Institute for Global Health, University of California, 74 New Montgomery Street, Suite 508 San Francisco, CA 94105, USA

1 Secretary of State for International Development. Elimi nating world poverty: making globalization work for the poor. London: Stationery Office, 2000.

2 Special survey. Globalization and its critics. Economist 2001 Sep 29:3-30.

\section{Struggle for public health and against economic globalisation go hand in hand}

EDITOR-Feachem's article misses the point of the anti-globalisation protests. ${ }^{1}$ To him, globalisation is openness to trade, ideas, investment, people, and culture. What he does not answer is whose culture, what terms of trade, which people, and who controls the investment.

Perhaps he should consider why the largest British group of demonstrators in Genoa marched under the name Globalise Resistance. In the report of the World Health Organization, which Feachem edits, Cornia comes closest to articulating those aspects of globalisation contested on the streets of Genoa-principally deregulation, trade liberalism, privatisation, and freedom for capital movement. ${ }^{2}$ That is economic neoliberalism. On that definition, he argues that there is no evidence that globalisation has improved economic growth and that with slow growth and frequent rises in inequality health improvements during the era of deregulation and globalisation decelerated perceptibly. The worst case was in the former Soviet Union where, he says, the excess mortality in Belarus, Ukraine, and the Russian Federation was an estimated 4 million between 1990 and 2000. ${ }^{2}$ The effects of economic globalisation primarily occur through increased instability, inequality, and charges for essential services.

Feacham's claim that globalisation increases the income of the poor relies on cross country comparisons. ${ }^{1}$ He merely reiterates the unsurprising correlation between trade, inward investment, and growth. He forgets that often the poorest countries are not able (because of sanctions, lack of tradeable goods, or war) rather than not willing to increase trade and attract investment.

Perhaps the most unlikely claim Feachem makes is that economic globalisation promotes democracy and human rights. For this he cites East Timor and Indonesia, forgetting that in Indonesia openness to multinationals, free trade in weapons, and support from developed countries went together with mass murder. Repeatedly, economic liberalisation has proved compatible with increased barriers to human migration. 
To provide an evidence based approach to globalisation and health it is necessary to analyse the impact of specific policies. Feachem does not even attempt to analyse the existing literature. One example is the World Trade Organisation's proposals to make it compulsory to open up all sectors of the economy that already contain some competitive element. ${ }^{3}$ In Britain this will almost certainly mean the NHS, as part privatisation is already being introduced through the private finance initiative. This has consistently meant fewer beds, fewer staff, and higher costs. ${ }^{4}$ Therefore, the struggle for public health and against economic globalisation go hand in hand.

James Woodcock member, Globalise Resistance 53C Darnley Road, Hackney, London E9 6QH

JW is a member of the campaigning organisation Globalise Resistance, which aims to bring together groups and individuals opposed to the global growth of corporate power.

Feachem RGA. Globalisation is good for your health, mostly. BMJ 2001;323:504-6. (1 September.)

2 Cornia GA. Globalization and health: results and options. WHO Bull 2001;79:834-42.

3 Pollock A. Rewriting the regulations: how the World Trade Organisation could accelerate the privatisation in healthcare systems. Lancet 2000;356:1995-2000.

4 Pollock A, Shaoul J, Rowland D, Plaver S. Public services and the private sector: A response to the IPPR's commission on public private partnerships. Health policy and health service research unit. London: University College London, 2001.

Globalisation is not good for your health

EDITOR-Feachem's article expresses complacency, beginning with the statement that globalisation-defined as openness to trade, ideas, people, and culture-brings benefits today as it has for centuries. ${ }^{1}$ This is true, but benefits to whom? The slave trade brought great benefits to the American plantation owners but not to the millions of Africans unwillingly globalised or their descendants. Similarly today, access to world markets brings ever increasing benefits to the large multinational companies and their stockholders, who are overwhelmingly based in the richest countries, but, in my experience, not to poor people in the countries being opened.

In Hyderabad, India, a city that Feachem would probably hail as a triumph of globalisation, there are motorways, palatial residential areas and hotels, and increasing numbers of sophisticated private hospitals. But the public Nilufar Children's Hospital, once the pride of the region, is run down and dilapidated, although it still attempts to deal with the bulk of childhood disease in the city.

Feachem does not mention trickle down, but that discredited theory seems to lie behind his faith in the benign effects of economic growth on health. He cites in evidence the World Bank, whose enforcement of structural adjustment in the 1980s and 1990s has been strongly linked to worsening health indices during that time. Economic growth, if linked to enlightened government, can bring health and social benefits, as it did in the years after the second world war in the United Kingdom-but the globalisers by and large do not mix with the poor and too readily assume that economic growth brings benefits to all sectors of society. Even in the United States this is patently not the case.

Feachem complains that those opposed to globalisation have no alternative to offer. I would point to the thousands of small initiatives to encourage local self sufficiency and income generation that have transformed lives among the poorest in many countries where they have been encouraged (and not flattened by competition from multinationals): on a larger scale, the example of Cuba shows what marked health benefits can accrue even in a poor country when the right priorities are adopted.

Openness is fine as long as it is mutually beneficial. The American and European globalisers expect countries to be open to their products, but the capital flow still tends to be one way. Is this globalism or neo-colonialism? I need much more evidence of health benefits to be convinced.

Andrew Porter consultant paediatrician

William Harvey Hospital, Ashford, Kent TN24 0LZ grampsyp@hotmail.com

1 Feachem RGA. Globalisation is good for your health, mostly. BMJ 2001;323:504-6. (1 September.)

\section{More openness is needed before more} trade

EDITOR-At the level of generalities, Feachem's observation that, in general, openness to trade improves national health does not match the accuracy of Keynes's famous statement "in the end we will all be dead." At a more specific level, and going back several centuries, histories of national economics show inconstant associations of free trade with economic growth. With the exception of Great Britain, most other large developed countries became industrialised and experienced economic growth under the shield of long periods of protectionism, most extended for the United States. Between 1950 and 1998 world exports have increased along an exponential-like curve by 20 times whereas the world's gross domestic product has grown in a linear curve by six times, which indicates, if anything, decreasing returns of trade on growth. ${ }^{3}$

The key difference between "neo-global" people, raising critical questions on current globalisation, and supporters of the al purpose answer "more trade" is that the former advocate independent analyses of specific issues whereas the latter rely on the postulate, verging on irrational faith, that unlimited trade of any kind (in food and guns, speculative capitals and productive investments, or polluting and ecology friendly industries) is able to produce unlimited growth, personal wealth, health, and-why not?-happiness.

Feachem's definition of globalisation as openness, with which one could concur, clashes with globalisation as currently observable. Openness implies a view opened to all citizens on who controls and regulates what, as well as explicit mechanisms of democratic checks. This is remote, in substance and form, from the secretive development of the (aborted) first version of the multilateral agreement on investments; from the coexistence in the World Trade Organisation-against the basic principle of separation of powers - of legislative and judiciary functions; and from the opaque daily conduct of huge speculative transactions heavily conditioning all economic activities. Immanuel Kant said that all actions concerning the rights of others that are incompatible with publicity are unjust. ${ }^{4}$ Before being asked to take a stance on future negotiations in the World Trade Organisation, health professionals must be fully informed of what exactly is being negotiated and what its foreseeable consequences on health in different countries are going to be.

Globalisation can be beneficial, not only in respect of health, provided that the great national movements for democracy, liberty, and social justice that took place in the 18th and early 19th centuries in nation states are now reproduced globally. Nothing less will do-certainly not more trade per se.

Rodolfo Saracci chairman

Marina Cuttini senior epidemiologist marina.cuttini@arsanita.toscana.it

Agencia Regional di Sanità Toscana (Regional Health Agency of the Tuscany Region), Via Vittorio Emanuele II 64, I-50134 Florence, Italy

1 Feachem RGA. Globalisation is good for your health, mostly. BMJ 2001;323:504-6. (1 September.)

2 Bairoch P. Mythes et paradoxes de l'histoire économique. Paris: La Découverte, 1999 .

3 The battle in Seattle. Economist 1999:353:23-8.

4 Kant I. Zum Ewigen Frieden. Italian translation: Per la pace perpetua. Milano: Feltrinelli, 1993.

perpetua. Milano: Feltrine 1993.

Giddens A, Hutton W. Fighting back. In: Hutton W, Giddens A, eds. On the edge: living with global capitalism London: Vintage, 2001:213-23.

\section{Globalisation of information could decrease effectiveness of healthcare provision}

EDITOR-Feachem in his paper praises globalisation. ${ }^{1}$ I challenge his opinion when he presents globalisation as openness to ideas, people, and culture. Let's take the case of health services. According to Feachem, globalisation should make health services more open to local needs, demands of the people, and their culture. Furthermore, it should greatly improve the management and delivery of healthcare services.

Our fear is that things could go the other way. Nowadays, the provision of public health services in low income countries, behind the justification of evidence based medicine and cost effectiveness, are provided in the same way in Zimbabwe, Sierra Leone, and Nicaragua. They offer standardised care to mothers, children, and for specific diseases (tuberculosis, malaria, AIDS, and a few others), leaving behind the rest. All is decided during technocrats' meetings in Geneva, Washington, or Brussels and translated into standardised guidelines. It becomes politically incorrect to challenge these new guidelines openly.

Direct observation of treatment for tuberculosis is one of these examples. It is a worldwide standardised strategy born in the era of globalisation that has been hard to 
challenge. It has made the provision of care more rigid and less adapted to patients' demands and cultures. The consequence has been that patients with tuberculosis, as seen in Vietnam and Nicaragua, have used private care, incurring useless expenses and receiving care of doubtful quality (J Macq et al, unpublished data). ${ }^{2}$ This has probably decreased the effectiveness of healthcare services in various contexts.

With regard to the dominant trends in international intervention in the health sector, it is unlikely that globalisation will promote openness to ideas, people, and culture. We should fear that it will impose worldwide uniformity in public healthcare provision, disconnecting health services from people and their culture, and decreasing their effectiveness.

Jean Macq researcher

Health Systems and Policy Department, School of Public Health, Free University of Brussels, CP597 Route de Lennik 808, B-1070 Brussels, Belgium jmacq@ulb.ac.be

1. Feachem RGA. Globalisation is good for your health, mostly. BMJ 2001:323:504-6. (1 September)

2 Lönnroth K, Tran TU, Le Ming T, Hoang TO Vinod D. Lönnroth K, Tran TU, Le Ming T, Hoang TQ, Vinod D.
Can I afford free treatment? Perceived consequences of health care provider choices among people with tuberculosis in Ho Chi Minh City, Vietnam. Soc Sci Med 2001;52:935-48

\section{Private health care in developing countries}

\section{Access cannot be equated simply with supply}

EDITOR-Zwi et al in their editorial suggest means by which governments in developing countries should try to harness private providers to improve the health of their citizens. ${ }^{1}$ A recent article by Whitehead et al, however, points to a medical poverty trap, created by the introduction of user fees for public services and the growth of out of pocket expenses for private services. ${ }^{2}$ The authors conclude that the main challenge in developing countries is to improve public health services and enable the poorest sections of society to obtain the health care they need.

India has experienced a massive growth in private health provision despite high public investment in health services. Several studies have shown that there is a marked reluctance to use free facilities even among the poorest sections in Indian society. For example, a study of health and health care among scheduled castes showed that 38\% sought private medical help when their children became ill, compared with $28 \%$ for government health facilities. ${ }^{3}$ Another study, which focused on the urban poor in Calcutta, concluded that public health facilities were used for emergency purposes but there was a preference for private practitioners for all other types of care. ${ }^{3}$ The implication of these studies is that access cannot be equated simply with supply but is dependent on locational, economic, and social access, as well as the quality of the services themselves.
At the same time as trying to make public services more responsive it is vital that resources are used efficiently in areas that maximise health improvement. At present, in India, over half of the health budget is spent on secondary and tertiary curative services, whereas better health outcomes could be achieved by investing in preventive measures. The emphasis on private healthcare provision may serve to distort these priorities even further.

Ian Mather public health scientist

Sam Ramaiah director of public health medicine Walsall Health Authority, Walsall WS1 1TE

1 Zwi AB, Brugha R, Smith E. Private health care in developing countries. BMJ 2001;323:463-4. (1 September.)

Whitehead M, Dahlgren G, Evans T. Equity and health sector reforms: can low-income countries escape the medical poverty trap? Lancet 2001:358:833-6.

por Gupta M, Che L Krishnan TN, eds Health poverty and development in India. Delhi: Oxford University Press, 1996.

\section{Strong public provision is only hope for} health care in developing countries

EDITOR-The editorial by Zwi et al, in which principles are described for the participation of private providers in delivering health care in developing countries, is important. ${ }^{1}$

I worked for five years in northern Nicaragua between 1989 and 1994. During that time I witnessed the strengths of the primary healthcare system developed by the Sandinista government in partnership with powerful community and social organisations. I also witnessed the entry of the World Bank and the International Monetary Fund into Nicaragua and the impact that this had on health and health care. One of the central beliefs imposed by these agencies was that local people must pay user fees for health and education. Funding from the public sector was drastically reduced, and the result was the effective conversion of free state health care into private, pay as you go, health care provided by the state. Local people, for example, had to sell their only cow, the sole source of milk for the family, to pay for necessary drugs, which led to further malnutrition. In parallel to this doctors provided private health care in clinics.

The effect of all of this was to deprive the poor majority of local people of access to health care. The cutbacks in public sector funding resulted in major reductions in malaria control and other public health measures. The result of this was a significant increase in cases of malaria and dengue fever.

Thus it is hard to imagine how the private sector can have anything but an inequitable effect on healthcare delivery in developing countries. Poor people will not be able to pay. This is particularly true when their livelihood is so vulnerable to international markets. So many people in Nicaragua have been devastated by the collapse in the international market value of coffee (resulting from a coffee glut as a result of the International Monetary Fund and World Bank recommending too many new countries to get into coffee production).

The hope for health care in countries such as Nicaragua is the phenomenal voluntary contribution made by the teams of health brigadistas up and down the country in combating common diseases such a diarrhoea and malaria. The internationa community can help by promoting fair trade, encouraging debt cancellation swapped for public health sector investment, and ensuring that vital drugs are not denied to poorer countries because of excessive costs and patent periods

Philip Crowley specialist registrar in public health medicine

Durham and Darlington Health Authority, Durham DH1 5XZ

philip.crowley@public-health.durham-ha.northy. nhs.uk

1 Zwi AB, Brugha R, Smith E. Private health care in developing countries. BMJ 2001;323:463-4. (1 September.)

\section{Impact of telemedicine must be defined in developing countries}

EDITOR-The editorial by Edworthy shows the dangers of external commentary on what is most useful for developing countries. ${ }^{1}$ How can we measure the comparative impact of teleconsultation in Uzbekistan or Cambodia with teleconsultation in snowbound northern Canada, telemetry in Norway supporting elderly people at home, or teleradiology avoiding long painful journeys in remote parts of the British Isles? What values do we use-economic, social, quality adjusted life years, consumer feedback, political position, or provider satisfaction?

More importantly, how do we measure the impact of telemedicine on the health systems of developing countries? Will strengthening secondary care for a few disadvantage basic primary care or environmental health for the many? Will investment in the required rural telecommunications be at the expense of providing drinkable water? Will developing countries too be seduced by the expensive impact of technology led tertiary care for the few, while ignoring the endemic impact of modified health related behaviour? Will opportunistic global traders exploit the vulnerable?

Most electronically available health knowledge is from the "developed" world-it may not be appropriate for developing countries. Remote experts may not know what treatments are available, affordable, or acceptable locally. Teleconsultation through a local clinician may initially strengthen local skills, but when used on a larger scale it may stifle the development of local resources and lead to a dependence on economically draining Western commercial exports of expertise online. The risks of globalisation reducing local autonomy have been reported. ${ }^{2}$

These are real issues, but they should be debated on the grounds of local values of appropriateness and priorities. The pull of needs, not the push of supply, should be the determinant. The voices of local experts, rather than external commentators, should be heard as the lead voices. ${ }^{3}$ Initiatives to identify culturally and locally relevant yet sound sites should be encouraged, and open 
debate initiated on the core issues. ${ }^{4}$ If telemedicine is to have any significant and safe impact in developing or other countries, global agencies such as the World Health Organization need to encourage and accumulate studies on its local impact, while also seeking a global framework to ensure its safety and ethics. ${ }^{45}$

Opportunities for benefit from telemedicine are great; so are the opportunities for harm. The future debate should be couched in terms of local health priorities and impact, and on global ethics to ensure sustainable assured solutions.

Michael Rigby senior lecturer

Centre for Health Planning and Management,

Darwin Building, Keele University, Keele,

Staffordshire ST5 5BG

1 Edworthy SM. Telemedicine in developing countries. BM 2001;323:524-5. (9 September.)

2 Rigby M. The management and policy challenges of the globalisation effect of informatics and telemedicine. Health Policy 1999;46:97-103.

3 Lam CLK. Knowledge can flow from developing to developed countries. BMJ 2000;321:830.

4 Rigby M. And into the 21st century: telecommunication and the global clinic. In: Rigby M, Roberts R, Thick M, eds. Taking health telematics into the 21st century. Abingdon: Radcliffe Medical Press, 2000:187-206.

5 Rigby M, Forsström J, Roberts R, Wyatt J. Verifying quality and safety in health informatics services. BMJ and safety in

\section{Comparative efficiency of national health systems}

\section{Developed countries must pay attention to wider issues in helping developing countries}

EDITOR-The contribution by Evans et al to the debate on the World Health Report 2000 deserves a comment on the wider issues of the findings rather than just on their validity. ${ }^{12}$ The outstanding feature of the league table on performance is how well most of the countries of the European Union have done and how poorly the countries of sub-Saharan Africa have performed in comparison. This raises the question of whether we in the Western world should be exercising an even greater responsibility than previously for the health of those living in poorer countries. ${ }^{3}$ The key activities that must be included in the context of richer Western nations helping poorer ones are the following.

World leaders, especially of the G8, should review the globalisation of the world economies with a view to removing unpayable debts, providing targeted economic aid directed towards sustainable development, making serious inroads into controlling the arms and drugs trade, and resolving conflict.

International agencies should accelerate the development of health and social welfare plans, provide grants for education and training, and encourage research into the most efficient and effective ways of improving health.

Voluntary and philanthropic agencies should enhance their outstanding work in the eradication of disease and famine, and the relief of disaster and poverty.
National governments should increase aid directed towards tackling major diseases, improving education, primary health care, and health promotion, and towards encouraging sustainable development in agriculture.

Political and religious leaders should set aside their differences and personal interests, and work together for the common good of the people they serve.

Corporate business should engage in ethical and non-monopolistic business practices, which avoid exporting unhealthy products, encourage fair trade, pay fair wages, and help to build up commercial and economic foundations.

Health professionals and academic institutions should carry out more basic research into the best methods to achieve health improvement in poor environments.

None of these proposals is revolutionary, and many may seem unrealistic and idealistic. The developed countries have already made major contributions to health improvement in developing countries. But if we don't pay attention to the wider issues, repercussions are likely for all of us. ${ }^{4}$ All we shall be doing is perpetuating the misery, suffering, and gross inequalities in health that developed countries are partly responsible for and can do something about.

Gordon Avery locum consultant in public health medicine

Iechyd Morgannwg Health, Swansea SA1 1LT gordon.avery@morgannwg-ha.wales.nhs.uk

1 Evans DB, Tandon A, Murray CJL, Lauer JA. Comparative efficiency of national health systems: cross national econometric analysis. BMJ 2001;323:307-10. (11 August.)

2 World Health Organisation. World Health Report 2000 Heath Health systems: improving performance. Geneva: WHO, 2000 Martin J. AIDS as a lever for reducing in
increasing solidarity. Bull WHO 1999;77:364.

increasing solidarity. Bull WHO 1999;77:364.
4 Sachs J. The links of public health and ecomomic development. Office of Health Economics. 8th annual lecture. London: OHE Office of 2001.

\section{Methodological problems were understated}

EDITOR-Evans et al present an unproblematic image of the methods and findings of the World Health Report 2000 despite the controversy that has surrounded the report on conceptual, methodological, and procedural grounds. ${ }^{1}$ I have published with others concerns about the report and draw attention to some issues relating to the paper. $^{2}$

"Healthy" (or "disability adjusted") life expectancy (DALE), the outcome measure used to estimate the efficiency of health systems, is presented as an unproblematic indicator, despite the lack of necessary data for many developing countries and the consequent arcane computational manipulation, often based on speculative assumptions, that was required to arrive at estimates for 191 countries. ${ }^{3}$ Uncertainty intervals were calculated for DALEs, but for the methods used the paper refers back to the report, which refers back to an internal discussion paper of the World Health Organization that has not yet been released on its website.

Criticism has also been expressed about the technical and ethical bases of the disabil- ity weights used in calculating DALE and about the meaning, usefulness, and validity of compressing data on mortality, morbidity, and disability into a single number. ${ }^{4}$ Many view death and non-fatal health outcomes as qualitatively different and incommensurable. It is difficult to see how a highly composite measure like DALE, which obscures epidemiological information, will help in meeting the stated objective of improving the evidence base for health policy. To effect change, policy needs to be specific and based on disaggregated data. Given the close correlation of DALE with standard life expectancy, it seems difficult to justify the effort and expense involved in constructing DALEs rather than using more transparent standard measures of mortality and morbidity. The approach to efficiency employed and the use of education rather than income to represent non-health-system determinants of health have also been questioned. ${ }^{5}$ Evans et al conclude that more money should be spent on health systems in poor countries and most countries would gain by using health resources more efficiently. Did we not know this already?

The section headed "validity of findings" makes no reference to the extensive literature discussing these and other problems, and Evans et al should have been asked to do this. The paper lends credence to the view that the World Health Report 2000 enterprise may owe more to institutional marketing than to science. ${ }^{5}$ Following pressure from countries and regions, the WHO will not update the assessments of health system performance this year but will initiate a scientific peer review of the methods to be employed in the future.

Malcolm Segall associate (retired fellow) Institute of Development Studies, University of Sussex, Brighton BN1 9RE m.segall@ids.ac.uk

1 Evans DB, Tandon A, Murray CJL, Lauer JA. Comparative metric analysis $B M J$ 2001.323.307-10.(11 Autional ecor

2 Almeida C, Braveman P, Gold MR, Szwarcwald CL, Ribeiro Almeida C, Braveman P, Gold MR, Szwarcwald CL, Ribeir $\mathrm{JM}$, Miglionico A, et al. Methodological concerns and recommendations on policy consequences of

3 Mathers CD, Sadana R, Salomon JA, Murray CJL, Lopez

Mathers CD, Sadana R, Salomon JA, Murray CJL, Lopez
AD. Estimates of DALE for 191 countries: methods and AD. Estimates of DALE for 191 countries: methods and
results. Geneva: World Health Organization, 2000. (Global results. Geneva: World Health Organization, 2000. (Global
programme on evidence for health policy discussion paper No 16.)

4 Arnesen T, Nord E. The value of DALY life: problems with ethics and validity of disability adjusted life years. BMJ 1999;319:1423-5. (27 November.)

5 Williams A. Science or marketing at WHO? A commentary on "World Health 2000." Health Econ 2001;10:93-100.

\section{Author's reply}

EDITOR-People living in poor countries have lower life expectancies, live a higher proportion of their lives in poor health, and spend less on health per person. Our best estimates suggest that their health systems are also less efficient than those in richer countries. ${ }^{1}$ We agree with Avery that richer countries should be much more active in seeking ways to improve the health of the world's poor. The World Health Organization has been a strong advocate for vast increases in the resources available for this 
purpose and continually collaborates with its member states to improve the performance of health systems on the basis of the best possible evidence. Its commission on macroeconomics and health will shortly report on the evidence linking development to improvements in health and estimates of the resources required to scale up health interventions for poor countries.

To improve the performance of health systems, policymakers require many types of information including levels of mortality, non-fatal health outcomes, and the morbidity associated with particular diseases, risk factors, and injuries. Our summary measure of population health, healthy life expectancy (HALE), builds on comprehensive and consistent estimates of fatal and non-fatal health outcomes. ${ }^{2}$ The methods have been subject to intensive debate, development, and peer review for well over a decade, and independent estimates have been made in several countries."

An interest in HALE does not prevent policymakers from considering the components separately-fatal and non-fatal health outcomes, and the morbidity associated with different causes. To facilitate this process, we have published this information along with HALE and the uncertainty intervals around key components. ${ }^{14}$ Contrary to Segall's contention, HALE provides more information than life expectancy-for a life expectancy of 70 , HALE varies from 57 to 65 , a major difference.

The WHO estimates are the first attempt to measure health system efficiency in the 191 members of the organisation in a consistent and comparable manner. ${ }^{2}$ Because of the importance of the topic and the interest this exercise stimulated, the director general, Gro Harlem Brundtland, decided that the performance of health systems will be assessed regularly by the WHO. To ensure that we benefit from continued external scientific advice, Dr Brundtland has established a consultative process part of which is a scientific peer review group to advise her on the methods to be used in the next round. Science only advances with open debate, and we are confident that the methods will develop rapidly. But the search for scientific perfection should not prevent policymakers receiving the best evidence scientifically available in the meantime.

David B Evans director ad interim

evansd@who.int

Ajay Tandon fellow

Global Programme on Evidence for Health Policy

Christopher L J Murray executive director

ad interim

Evidence and Information for Health Policy

Jeremy A Lauer economist

Global Programme on Evidence for Health Policy, World Health Organization, CH-1211 Geneva, Switzerland

1 World Health Organization. World health report 2000 Health systems: improving performance. Geneva: WHO, 2000. 2 Mathers CD, Sadana R, Salomon JA, Murray CJL, Lopez AD. Healthy life expectancy in 191 countries, 1999. Lancet, 2001;357:1685-91.

3 Wolfson MC. Health-adjusted life expectancy. Health Rep 1996;8:41-6.
4 Salomon JA, Mathers CD, Murray CJL, Ferguson B. Methods for life expectancy and healthy life expectancy uncertainty analysis. (GPE Discussion Paper No. 10.) Geneva: World Health Organization, 2001. (Also available at www.who.int/evidence.)

\section{To improve health care system's} performance, drink red wine

EdiTor-Evans et al, from the World Health Organization, compare the efficiency of national health care systems. ${ }^{1}$ Efficiency relates to the health you get for the money you spend. The first question then is how to quantify health. Evans et al use healthy life expectancy and thousands of questionable assumptions about morbidity. They fail to explain why they do not take life expectancy (strongly correlated to healthy life expectancy) and hard death rates. They then correct this measure for the minimum achievable health in the absence of a health system. No mention is made of the data and methods used in this enterprise- either in this paper or in that cited.

Evans et al explain health by healthcare expenditure and schooling. They state, "We did not include income per capita, because income is highly correlated with health expenditure," which is a surprisingly easy way of solving the problem of colinearity. Any housewife (and a wealth of literature not addressed by the authors) ${ }^{34}$ will tell you that it is income that generates expenditure, and not the inverse. Tall basketball players have large shoe sizes and take many rebounds. Buying larger shoes won't increase their performance.

I will explain the results, duly omitted by the authors. All oil producing countries of the Middle East rank highly. Life expectancy is mediocre, levels of healthcare funding are poor ( $<4 \%$ of gross domestic product), levels of (female) schooling are low, and minimum achievable health is probably very low. Because their actual wealth is not taken into account, the life expectancy "expected" by poor schooling, poor funding of health care, and a history of poverty is even more mediocre than that observed, meaning that the healthcare service is good.

The healthcare systems of Mediterranean countries are very efficient. These countries experience a remarkably low (cardiovascular) mortality, which is often attributed to the drinking of red wine. Healthcare funding is again poorer than average, so the expected life expectancy is lower than the observed.

Zimbabwe is the poorest performer of all. Zimbabwe funded its health care and schooling better than other sub-Saharan countries. Better funding and higher literacy rates condemn it as inefficient because its expected life expectancy is higher.

Evans et al's conclusions about healthcare efficiency ought to be summarised as follows: keep your people ignorant, underfund your healthcare service, find oil, and drink red wine.

Luc Bonneux researcher

Department of Public Health, Erasmus University Rotterdam, PO Box 1738, 3000 DR Rotterdam,

Netherlands

bonneux@mgz.fgg.eur.nl
1 Evans DB, Tandon A, Murray CJL, Lauer JA. Comparative efficiency of national health systems: cross national econometric analysis. BMJ 2001;323:307-10. (11 August.)

2 Evans DB, Bendib L, Tandon A, Lauer JA, Ebener C, Hutubessy R, et al. Estimates of income per capita, literacy, educational attainment, absolute poverty, and income GINI coefficients for the world health report 2000. Geneva: World Health Organization, 2000. (Global programme on evidence for health policy discussion paper No 7.)

3 World Bank. Investing in health. World development report. New York: World Bank, 1993

4 Navarro V. Assessment of the world health report 2000. Lancet 2000;356:1598-601.

\section{Managing term breech deliveries}

\section{External cephalic version should be routine clinical practice in UK}

EDITOR-Shennan and Bewley summarise the dilemma in managing term breech presentation. ${ }^{1}$ But despite the recommendation of the Royal College of Obstetrics and Gynaecology of external cephalic version for all uncomplicated term breech pregnancies, the procedure is apparently not part of routine clinical practice in the United Kingdom. ${ }^{2}$ The reasons for this include local, national, and training issues.

A systematic inquiry into the practice of external cephalic version in the United Kingdom is required. Questionnaire studies suggest that few British centres offer external cephalic version, although these incur selective reporting bias. ${ }^{3}$ Uptake of external cephalic version is low because of patients' refusal, contraindications to the procedure, and failure to diagnose breech presentation ( $\mathrm{R}$ Varma et al, 29th British congress of obstetrics and gynaecology, Birmingham, July 2001). Better antenatal detection of breech presentation and broadening the inclusion criteria to include higher risk pregnancies may enhance the impact of external cephalic version. Counselling by health professionals influences the decision making process, and this should be consistent with and supplemented by local success rates of external cephalic version.

Further training of practitioners in external cephalic version is needed, especially as there are no recognised training courses nor is it listed as an objective in the training syllabus for specialist registrars of the Royal College of Obstetrics and Gynaecology. In contrast, the syllabus for the royal college's subspecialist training in fetomaternal medicine states that the trainee should be expert in the procedure, which has a long learning curve and so would be best started early on in professional training rather than when subspecialising.

Obstetricians' inexperience in managing vaginal breech delivery has contributed to adverse outcome and is likely to increase as a result of the current change in practice. ${ }^{14}$ Nevertheless, it is impossible to deliver all term breech pregnancies by caesarean section. The mother may insist on vaginal delivery, breech labour may be precipitate, and there are special situations such as the second fetus in twins. It is therefore imperative that trainees continue to receive training in vaginal breech delivery. 
A retrospective study of external cephalic version $(n=108)$ versus nonexternal cephalic version $(n=254)$ for term breech presentation in 1998-2000 in our hospital showed that $4.0(95 \%$ confidence interval 2.8 to 6.8 ) attempted procedures were required to prevent one caesarean section ( $\mathrm{R}$ Varma et al, 29th British congress of obstetrics and gynaecology, Birmingham, July 2001). As implied by Shennan and Bewley, obstetricians no longer recommend trial of vaginal breech delivery. Thus, applying this study's findings to current practice, the effectiveness of external cephalic version increases, such that 2.2 (1.8 to 2.8) attempted procedures may prevent one caesarean section. External cephalic version is therefore one of the most effective procedures in modern obstetrics and is both safe and cost effective.

Rajesh Varma specialist registrar obstetrics and gynaecology

drrajesh@varma16.freeserve.co.uk

David Horwell consultant obstetrician and gynaecologist

Luton and Dunstable NHS Trust, Luton, Bedfordshire LU4 0DZ

1 Shennan A, Bewley S. How to manage term breech deliveries. BMJ 2001;323:244-5. (4 August.)

2 Royal College of Obstetricians and Gynaecologists. The management of breech presentation. London: RCOG, 1999. (Clinical guideline No 20.)

3 Burr RW, Johanson RB, Jones P, et al. A survey of obstetricians' attitudes to the management of term breech. J Clin Excellence 1999;1:35-40.

4 Confidential Enquiry into Stillbirths and Deaths in Infancy. 7 th annual report. London: CESDI Secretariat, 2000.

\section{Patient values are crucial for good medical decision making}

EDIToR-Shennan and Bewley in their editoral on managing term breech deliveries understate the importance of patients' values in the decision making process. ${ }^{1}$ If external cephalic version is unsuccessful, the options are to deliver vaginally or by caesarean section. The actual conclusion of the multicentre study was that caesarean section is the safer option for the baby, but many practising clinicians have extrapolated this to mean that the best decision for most women in developed countries is to avoid vaginal breech delivery and deliver by caesarean section. ${ }^{2}$ This type of reasoning assumes that both modes of delivery represent equivalent disasters to all women. Individual women place different values on birth processes and outcomes from obstetricians. ${ }^{3}$ These differences must be recognised and respected in obstetric decision making. Anything less will validate accusations of paternalism.

A good decision is choosing the option that is most likely to result in the most satisfactory outcome for the patient. It requires a combination of the research evidence, the patient's values, and the clinician's professional judgment. Most clinicians and patients combine these components intuitively to arrive at a decision, but intuition is subject to many biases (anchoring, availability, representativeness, or framing effect) and hence errors of judgment when complex decisions need to be made.

A more objective approach is decision analysis. ${ }^{4}$ In a small pilot study, we interviewed nine midwives who had a history of successful vaginal deliveries. We asked them to imagine they were pregnant, with a breech presentation at term, and for each woman we obtained value scores for the eight possible outcomes after delivery. They were shown the results of the multicentre study and, after perusal, were asked to choose their preferred mode of delivery. Subsequently, their individual value scores for each outcome were inserted into a computerised decision tree, which had been constructed using the probabilities from the multicentre study. This generated a "logical" decision for each woman, which was then compared with her "actual" decision. In all the women, the logical decision was to attempt a vaginal delivery, but only two of the nine women had actually chosen this option. Most had chosen the option of planned caesarean section, yet this was less likely to give them the outcome they most desired (vaginal delivery, healthy mother, and healthy baby).

There is a tendency to make illogical decisions, despite access to good research evidence. Clinicians must therefore remember the importance of patient values and should be prepared to embrace decision aids, especially when faced with complex decisions. This is the way to convert good evidence into good practice.

Amaju Ikomi consultant

Maj.Ikomi@virgin.net

Dattakumar Kunde senior specialist registrar Department of Obstetrics and Gynaecology, Basildon Hospital, Basildon, Essex SS16 5NI

1 Shennan A, Bewley S. How to manage term breech deliveries. BMJ 2001:323:244-5. (4 August)

2 Hannah ME, Hannah WJ, Hewson SA, Hodnett ED, Saigal S, Willan AR, for the Term Breech Trial Collaborative Group. Planned caesarean section versus planned vagina birth for breech presentation at term: a randomised multicentre trial. Lancet 2000;356:1375-83.

3 Vandenbussche FP, De Jong-Potjer LC, Stiggelbout AM, Le Cessle S, Keirse MJ. Differences in the valuation of birth outcomes among pregnant women, mothers, and obstetricians. Birth 1999;26:178-83.

4 Thornton JG. Decision analysis in obstetrics and gynaecology. Balliere's Clin Obstet Gynaecol 1990;4:857-66.

\section{Term breech trial does not provide} unequivocal evidence

EDITOR-In their editorial on managing breech deliveries at term, Shennan and Bewley say that the term breech trial provides unequivocal evidence that women with a breech presentation at term who plan a caesarean section will have a baby less likely to die or have a serious outcome than those who plan a vaginal delivery. ${ }^{12}$ This statement must be qualified by the caveat "if managed under the protocol for vaginal breech delivery specified for this trial."

This protocol would not have been acceptable at either of the United Kingdom's teaching hospitals at which I have trained. Normal results on contemporary ultrasonography (excluding intrauterine growth retardation, excessive growth, abnormal liquor volume, abnormal presentation, and fetal anomaly), spontaneous labour, rapid progress, and a short second stage are considered essential prerequisites to vaginal breech delivery. A first stage of 18 hours, a second stage of three and a half hours, and liberal use of induction and augmentation would not be allowed.

Analysis of the more detailed information concerning the perinatal deaths published in the online version of the paper suggests that induction, augmentation, and low birth weight are risk factors for adverse outcome. Of the 14 deaths in the intended vaginal delivery arm, nine (64\%) were either induced or augmented. Five deaths $(5 / 14$; $36 \%$ ) were of small for gestational age infants. Overall, in the intended vaginal delivery arm there were only three deaths involving labours that were not induced or augmented, or in which accurate prelabour ultrasound assessment might have been reasonably expected to have precluded a trial of labour on the basis of possible intrauterine growth retardation. This compares with three neonatal deaths in the intended caesarean section group, one after a difficult vaginal delivery, one when the baby was small for gestational age (2300 g), and one after a ruptured myelomeningocele.

If the analysis is restricted to the subgroup of countries where perinatal mortality is low there were no perinatal deaths in the planned caesarean section group versus three in the planned vaginal delivery group. Labour in these three women was either induced or augmented, and one resulted in the death of the (presumably) undiagnosed twin $(1150 \mathrm{~g})$. On the basis of these results, it is not possible to say unequivocally that planned caesarean section is safer for the baby, so long as accurate antenatal ultrasound assessment is performed and labour is neither induced nor augmented. After the results of the term breech trial it will, however, be necessary for any unit continuing with a policy of planned vaginal breech delivery to audit their results to ensure that such a policy remains safe.

David Somerset lecturer in obstetrics and gynaecology University of Birmingham, Birmingham Women's Hospital, Birmingham B15 2TG d.a.somerset@bham.ac.uk

1 Shennan A, Bewley S. How to manage term breech deliveries. BMJ 2001;323:244-5. (4 August.)

2 Hannah ME, Hannah WJ. Hewson SA, Hodnett ED, Saigal S, Willan AR, for the Term Breech Trial Collaborative Group. Planned caesarean section versus planned vaginal birth for breech presentation at term: a randomised multicentre trial. Lancet 2000;356:1375-83.

\section{Authors' reply}

EDITOR-We endorse all that Varma and Horwell say regarding the importance of external cephalic version. Their data on the relative increase of effectiveness of external cephalic version in the light of the findings of the term breech trial is interesting. We agree that training of all obstetricians is essential, not only those subspecialising.

We said in our editorial that some women will choose vaginal delivery even when the evidence of harm was conclusive. 
We made no value judgment on who should or should not have a vaginal breech delivery but stated the evidence for interpretation. Results should not be extrapolated to other groups such as twins and premature birth.

Ikomi and Kunde attribute values to the outcome of a vaginal delivery, healthy mother, and healthy baby in their "logical" decision process. We caution against the inherent bias of their pilot study: interviewing midwives after a normal outcome is probably as inappropriate as asking an obstetrician how they would like to deliver. If faced with a $1.6 \%$ (planned caesarean section) versus a $5 \%$ (planned vaginal delivery) chance of serious morbidity or death, we would not call it "illogical" to opt for a caesarean section (assuming an external cephalic version had not worked), even if a vaginal delivery was desired.

Somerset says that if a less liberal approach to vaginal delivery were adopted for the term breech baby, the excess of morbidity and mortality over planned caesarean section may not be apparent. However, even with the stated criteria within the term breech trial, almost half of women who planned a vaginal delivery still required a caesarean section. We do not believe the management of breech presentation in the trial was particularly wayward or unacceptable. For example, only one women out of 558 had a first stage of $>18$ hours, and more than $97 \%$ of women pushed for less than 90 minutes.

Care must be taken with post hoc analysis of subsets of data as Somerset has performed. Results that arise from predefined primary endpoints in a well conducted randomised controlled trial are compelling. Given the comparatively low prevalence of a breech with an adverse event and the unlikely chance of a successful vaginal breech delivery using even more stringent criteria, we do not think any individual unit auditing their practice will be able to ensure safety. It has taken a large international randomised controlled trial to show evidence of harm.

Andrew Shennan senior lecturer, maternal and fetal research unit

Susan Bewley clinical director, women's health directorate

St Thomas's Hospital, London SE1 7EH

\section{Steroid injections are helpful in rotator cuff tendinopathy}

EDITOR-Speed discussed corticosteroid injections in tendon lesions. ${ }^{1}$ We agree that there is a lack of good randomised trials in this field, but we disagree with his conclusion that in rotator cuff tendinopathy, range of movement but not pain is improved by steroid injection.

Speed comments that analysis of the pooled data in two prospective randomised trials showed an improvement in abduction but not pain after steroid injections. It is not clear if this is compared with anti- inflammatory treatment or placebo. When examined individually, however, these papers concluded that triamcinolone significantly improved pain at four weeks compared with placebo and showed nonsignificant benefits compared with naproxen or diclofenac. ${ }^{23}$

Furthermore, in our experience, steroid injections provide pain relief sufficient to obviate surgical treatment in a proportion of patients with tendinopathy without rotator cuff tears. This is supported by a prospective randomised controlled double blind clinical study from the Hospital for Joint Diseases in New York that shows the efficacy of steroid injections in providing pain relief for the subacromial impingement syndrome. ${ }^{4}$ In this study, 40 patients with confirmed signs of impingement in the absence of a rotator cuff tear, pain, and range of movement improved noticeably during up to six months of follow up when compared with local anaesthetic alone.

We think that in the case of rotator cuff tendinopathy steroid injections are a worthwhile addition to the physician's list of options.

Simon J Mellor orthopaedic specialist registrar Vipul R Patel consultant orthopaedic surgeon St Helier Hospital, Carshalton, Surrey SM5 1AA

1 Speed CA. Corticosteroid injections in tendon lesions. BMJ 2001;232:382-6. (18 August.)

2 Petri M, Dobrow R, Neiman R, Whiting-O'Keefe O Seaman WE. Randomised double blind placebo controlled study of the treatment of the painful shoulder. Arthritis Rheum 1987;30:1040-5.

3 Adebajo AO, Nash P, Hazelman BL. A prospective double debajo AO, Nash P, Hazelman BL. A prospective double blind dummy placebo controlled study comparing Triaminolone Hexacetonide injection with oral Diclofenac 5 $\mathrm{mg}$ tds in patients with rotator cuff tendinitis. J Rheumato

4 Blair B, Rokito AS, Cuomo F, Jarolem K, Zuckerman JD Efficacy of injections of corticosteroids for subacromia impingement syndrome. J Bone Joint Surg 1996;78-A $1685-9$

\section{Teenage pregnancies are influenced by family structure}

EDITOR-Since up to $80 \%$ of unintended pregnancies result from contraceptive failure, McLeod cautions that differential access to contraceptive services may be only one component affecting local variation in rates of teenage pregnancy. ${ }^{12}$ She mentions the well established association between socioeconomic deprivation and teenage pregnancies.

She does not, however, mention the equally well established link between one parent families and teenage pregnancy, which is graphically illustrated by (although not highlighted in the text of) the 1999 social exclusion report on teenage pregnancy. ${ }^{3}$ Young people aged 14-17 who live in a two parent family are less likely to have ever had sexual intercourse than young people living in any other family arrangement, even after adjusting for potentially confounding factors such as race, age, and socioeconomic deprivation. ${ }^{4}$

This is hardly surprising, as children whose parents talk to them about sexual matters and provide sexuality education at home are more likely than others to postpone sexual activity. ${ }^{4}$ There is likely to be an overall greater chance of good communication to both sons and daughters if there are two parents rather than one. Cohabitations are four times more likely to break up than marriages and less than $4 \%$ of cohabitations last 10 years or more, ${ }^{5}$ so children born outside of marriage stand little chance in their teenage years of being in the optimal family structure associated with the lowest risk of unplanned pregnancy. Without better marriage education and support in the United Kingdom, teenage pregnancy rates are likely to remain high even with increasing availability of contraceptives.

Trevor Stammers tutor in general practice St George's Hospital Medical School, London SW17 0RE

stammtg@globalnet.co.uk

1 Pearson VAH, Owen MR, Phillips DR, Pereira Gray DJ, Marshall MN. Pregnant teenagers' knowledge and use of emergency contraception. BMJ 1995;310:1644.

2 McLeod A. Changing patterns of teenage pregnancy: population based study of small areas. BMJ 2001:323:199203. (28 July.)

3 Social Exclusion Unit Teenage preonancy. London: Stationery Office, 1999:33, fig 19.

4 Blake SM, Simkin L, Ledsky R, Perkins C, Calabrese JM Blake SM, Simkin L, Ledsky R, Perkins C, Calabrese JM. Effects of parent-child communications intervention on young adolescents' risk for onset of ealy intercourse. Fam

5 Morgan P. Marriage-lite: The rise of cohabitation and its consequences. Institute for the Study of Civil Society (CIVITAS) London, 2000:13.

\section{Inequalities and research need to be balanced}

EDITOR-Smith is correct in saying that indifference to the social impact of research has produced a serious imbalance in the research portfolio. ${ }^{1}$ Reporting on my own field, public health, the health select committee recently concluded that the public health function had been dominated for too long by a culture, mind set, and training scheme that emphasise the epidemiology and science of public health rather than its practice in bringing about change. Smith talks about the likely social benefits of research on incontinence pads, and in my 26 years of varied health research the work that has had the most widespread practical, professional, and policy impact was just such a low tech study, of footcare for frail older people. ${ }^{2}$

In 1991 Sir Michael Peckham's visionary strategy for the United Kingdom, Research for Health, was intended to change the balance of health research towards science more relevant to health service needs. But the medical schools (mea culpa, too) had a vested interest in getting more money to do the same old things. Along with the higher education funding council for England, which refused to assess relevance as any dimension of research quality, a small number of the old universities sabotaged the NHS agenda of research for health. For health service employees attempting to do research, there is now a national quality initiative to develop research governance. ${ }^{3}$ This does aspire to a quality research culture that 
links research to national priorities and needs. Unfortunately, the only public body it identifies with any responsibility to ensure high quality research that offers benefits to participants, services, and society at large is the local research ethics committee, whose members are most unlikely to have any skills in measuring the social impact of research.

One group with a clear interest in evaluating the social impact of research and development is the Academy of Learned Societies for the Social Sciences, and this has made a promising start by addressing research around health inequalities. ${ }^{4}$ It provides clear guidance for public health researchers as to where we should be developing our indicators of impact-reducing those social inequalities that disadvantage the long term health of populations. This year the Department of Health is inviting public health professionals to suggest appropriate indicators for tackling health inequalities, and it seems opportune to use some of these same indicators to assess the health impact of research.

Woody Caan public health specialist in research and development

International Centre for Health and Society,

University College London, London WC1E 6BT

woody@public-health.ucl.ac.uk

WC is an unpaid adviser on research governance in health authorities to the NHS research and development managers' forum.

1 Smith R. Measuring the social impact of research. $B M$ J 2001;323:528. (9 September)

2 Bradley A, Campbell J, Milns D, White D, Caan W. Getting podiatry research off the ground. $\mathrm{Br} J$ Ther Rehabil 1999;6:14-6.

3 Department of Health. Research governance framework for health and social care. London: $\mathrm{DoH}, 2001$.

4 Forbes I, ed. Health inequalities: poverty and policy. London Academy of Learned Societies for the Social Sciences, 2000.

5 Department of Health. Tackling health inequalities. Consultation on a plan for delivery. London: $\mathrm{DoH}, 2001: 33-7$.

\section{Phytoestrogens and menopause}

\section{Published evidence supports a role for phytoestrogens in menopause}

EDITOR-In her editorial on phytoestrogen therapy for menopausal symptoms Davis has overlooked published information that would have argued against claims that there is no good evidence that isoflavone phytoestrogens are any better than placebo. ${ }^{1}$ In fact, good published evidence shows that they are effective not only for managing acute symptoms of the menopause but also for improving cardiovascular and bone health.

According to Davis, the published data cited showed that an over the counter tablet preparation of isoflavones extracted from red clover had no greater benefit than placebo for vasomotor symptoms. ${ }^{2}$ Although it is correct that in this study the mean response in the placebo group was not statistically different from the treatment group, this was not because of a lack of effect in the treatment group but because of inadvertent or deliberate consumption of isofla- vone containing foods in the placebo group. Both groups responded with reduced flushing. This was shown by measuring urinary concentrations of isoflavones in both groups. Analyses showed strong positive correlation between reduction in symptoms and urinary isoflavone concentrations.

Of greater concern is the fact that Davis overlooked published evidence for cardiovascular and bone effects. In double blind placebo controlled trials, systemic arteria compliance, a measure that correlates with improved risk of cardiovascular disease, was significantly improved in women taking a red clover isoflavone supplement, the rate of loss of bone density in perimenopausal women taking the same supplement was halved over a 12 month period, and concentrations of high density lipoprotein cholesterol were improved (C Atkinson et al, 82nd annual meeting of the Endocrine Society, Toronto, June 2000). ${ }^{3}{ }^{4}$ Data reported by Clifton-Bligh et al, who used a modified and more concentrated red clover isoflavone supplement, indicated not only reduced bone loss but improved bone density as well as increased concentrations of high density lipoprotein cholesterol after only three months of supplementation. ${ }^{5}$ It is a pity that editorial comment can be used not only to present a view biased against natural therapies, but that peer reviewed published data have been overlooked to achieve this outcome.

Alan J Husband research director

Novogen Limited, 140 Wicks Road, North Ryde, New South Wales 2113, Australia

In addition to a fractional professorial appointmen at the University of Sydney, AJH is Research Director of Novogen Limited, an Australian pharmaceutical company involved in developmen and manufacture of red clover isoflavone supplements and research and development of new prescription drugs based on synthetic isoflavone structures.

1 Davis SR. Phytoestrogen therapy for menopausal symptoms? BMJ 2001;323:354-5. (18 August)

2 Baber RJ, Templeman C, Morton T, Kelly GE, West L. Randomised placebo-controlled trial of an isoflavone supplement and menopausal symptoms in women. Climacteric 1999;2:85-92

3 Nestel PJ, Pomeroy S, Kay S, Komesaroff P, Behrsing J, Cameron JD, et al. Isoflavones from red clover improve ystemic anteriat compliance but not plasma lipids in systasma lipids 1999:84:895-8

IV Isoflavones and breast cancer.

4 Woodside JV, Campbell MJ. Isoflavones and breast cancer. J Br Menopause Soc 2001;7(suppl1):17-21.

5 Clifton-Bligh PB, Baber RJ, Fulcher GR, Nery ML, Moreton T. The effect of isoflavones extracted from red clover (Rimostil) on lipid and bone metabolism. Menopaus 2001;8:259-65.

Pharmacological attributes of plant based drugs should be discussed widely

EDIToR-I am glad that there is more mainstream discussion on the pharmacological action and toxicity of plant based drugs. These substances have complex mechanisms of actions and may be safe to take in some circumstances but not in others. For example, phytoestrogens may stimulate or inhibit the growth of breast tumours, depending on the amounts taken. ${ }^{2}$

Most pharmacy or medical schools stopped teaching pharmacognosy long ago and are now scrambling to revive them with the increased interest in alternative treatments. It is time we once again look at any substance that is used to treat, prevent, or mitigate a medical condition with the same scientific curiosity and scrutiny, irrespective of its source.

\section{Mario de Lemos provincial drug information} coordinator

Systemic Therapy Program, British Columbia Cancer Agency, 600 West 10th Avenue, Vancouver British Columbia, Canada V5Z 4E6

mdelemos@bccancer.bc.ca

1 Davis SR. Phytoestrogen therapy for menopausal symptoms? BMJ 2001;323:354-5. (18 August.)

2 de Lemos ML. Fffects of soy phytoestrogens genistein and daidzein on . Erects of soy phytoestrogens genistein and daidzein on breast cancer growth. Ann Pharmacother
(in press).

\section{Does lack of video mean GP registrar is not competent GP?}

Editor-Although Bahrami clearly feels sympathy for the unfortunate and blameless general practice registrar whose assessment video was lost, this does not prevent him from saying that the registrar could not be considered competent and allowed to work as a general practitioner. ${ }^{1}$ Why not? Is there any law or edict by the General Medical Council that would have prevented the general practitioners' education authorities from recognising his competence, in view of the overwhelming evidence that he was perfectly able to work as a general practitioner? He had passed all other parts of his assessment and had the backing of his trainers.

Most general practitioners in the United Kingdom have never completed a summative assessment because they completed training before 1998. They have certainly never had videos of their consultations assessed in the way described by Bahrami. Does this render them incompetent?

Who would have suffered if the general practitioners' education authorities had allowed this doctor to qualify as a general practitioner, rather than ruining his career in the United Kingdom by sticking so rigidly to the letter of the law? Who would have complained about such an application of flexibility and common sense? Conversely, who has gained from the insistence that, without a video, he could not practice as a general practitioner? The use of videos may or may not be helpful. The inflexible application of the rules in this case was clearly not helpful at all.

Anisur Rahman senior lecturer in rheumatology Centre for Rheumatology, University College London, Arthur Stanley House, 40-50 Tottenham Street, London W1T 4NJ

anisur.rahman@btinternet.com

1 Bahrami J. The lost video. BMJ 2001;323:581. (9 September.)

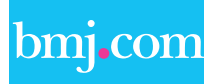

\section{Rapid responses}

Correspondence submitted electronically

is available on our website 